\section{Dispute over money may foil US AIDS vaccines trial}

\author{
Washington. An agreement between the \\ US National Institutes of Health (NIH) and \\ the Department of Defense (DoD) to test \\ three therapeutic AIDS vaccines is about \\ to collapse, with the $\$ 20$ million appropri- \\ ated last autumn by Congress reverting to \\ the DoD for other AIDS research
} work. NIH, which was to conduct the clinical trials under an agreement brokered last month by the White House (see Nature 362, 581; 1993 ), is ready to announce that it cannot afford to pay $\$ 10$ million to MicroGeneSys, the Connecticut company that supplies one of the three vaccines.

$\mathrm{NIH}$ scientists say that it would be "unprecedented" to pay a company for a product being tested for efficacy. Frank Volvovitz, president of MicroGeneSys, says his company will provide the vaccine at cost because "we're a small firm and we can't afford to do it otherwise".

The comparative trial proposed by NIH cannot go ahead without MicroGeneSys because Congress stipulated a "large-scale clinical investigation of the gp-160 vaccine" and the Connecticut company is the only US producer of gp-160. The other two proposed participants in the trial -
Genentech and Chiron, both of California - have promised to provide their gp- 120 vaccines free.

The Army had originally planned to conduct a large-scale trial using only MicroGeneSys's product — called VaxSyn
- and a placebo. But complaints from AIDS activists and federal researchers led to an agreement that NIH would perform a comparative trial of three competing vaccines. The collapse of the agreement, and the accompanying public recriminations between Army and NIH researchers, will be seen as a failure of management on the part of the Clinton administration.

If $\mathrm{NIH}$ withdraws from the agreement, the \$20 million will revert to the Army's AIDS research budget, giving the Army

the right to proceed with a single-vaccine trial. But a more likely outcome is believed to be an extension of existing vaccine trials that the Army is planning in Thailand. The only vaccine to be used in the first stages of those trials is MicroGeneSys's gp- 160 .

An Army spokesman referred enquiries about problems with the agreement to NIH. "Our health affairs people have talked to $\mathrm{NIH}$ and the ball is in their court", the spokesman said.

$\mathrm{NIH}$ officials referred enquiries to the office of their political boss, health secretary Donna Shalala, where a spokesman said that the two departments were "still working out an agreement".

But people close to the negotiations said late last week that NIH might withdraw from the trial "any day now". They blame MicroGeneSys for insisting on payment and described the recent events as driving "the final nail in the coffin of scientific integrity

of Army research".

VaxSyn is the oldest product to be offered as a possible therapeutic vaccine for carriers of HIV (human immunodeficiency virus), and it has been tested more extensively for safety and efficacy than any rival. But its value as a vaccine is a source of fierce scientific controversy, which increased after Congress appropriated money specifically for efficacy trials of gp-160 as a therapeutic vaccine.

Colin Macilwain

\title{
India moves ahead cautiously on US AIDS project
}

New Delhi \& Washington. India's leading medical research administrator is trying to allay concern about collaboration with US scientists on preventive AIDS vaccine trials by promising that the trials will not take place without the permission of the Indian government.

Fears have been expressed at Pune in Maharashtra state, where the joint project is now identifying for future trials some 2,500 people at high risk of contracting HIV, that the sample may be used for tests of vaccines and other treatments that are not allowed in the United States. Such accusations have been denied by the US National Institutes of Health (NIH), which is financing the project.

Pune is one of nine sites in poor countries selected last autumn by NIH to receive \$3million in awards in the first year of its Preparing for AIDS/HIV Vaccine Evaluation (PAVE) scheme. The programme matches US researchers with local teams to prepare samples of the population for trials to begin as early as mid-1994.

Most of the sites are in African countries with histories of similar work and little chance of opposition. India, however, has until recently been sceptical of collaboration with US scientists.

The Pune project is a collaboration between the newly created National AIDS Research Institute (NARI) of the Indian Council of Medical Research (ICMR) and researcher Robert Bollinger of Johns Hopkins University in Baltimore, Maryland. Researchers hope to find 2,500 prostitutes and patients at clinics for those with sexually transmitted diseases and to develop a way to track them through future trials of vaccines and other treatments.

The Indian government has reaffirmed its policy not to allow any vaccine to be tested in India unless it has first been tested in its country of origin. ICMR directorgeneral S.P. Tripathy says that the decision to prepare the sample does not imply permission for a trial. "The Indian government has to make its own decision whether or not it would allow the trial", he says. "There is a possibility that India may not undertake a trial at all."

US officials expect to face problems with trials in India but insist that, according to
Bob Fischer, an international health officer dealing with PAVE at NIH, "nothing we do overseas won't be done in the US. And where people don't want trials, we won't have them."

Bollinger says that PAVE has been misunderstood in India. It is a series of preparations, not a clinical trial, he says, adding that Indian agencies maintain control of it despite $\$ 800,000$ in US funding.

Some 310 people are known to have died of AIDS in India since the first case of HIV was reported in 1986, and it is estimated that 500,000 Indians carry the virus. Half of the estimated 50,000 injected drug users in northeast India are believed to be infected and Korshed Pavri, a retired ICMR virologist, says that someone is infected every five minutes in Bombay's red-light district.

Last year, India created the National AIDS Control Organization to tackle the problem. But its $\$ 100$-million budget over five years - mostly obtained as a loan from the World Bank - will be spent on hospital equipment, advertising campaigns and condom promotion, not research.

K.S. Jayaraman \& Colin Macilwain 